\title{
La presencia de José Figueres en México: del unionismo a la insurrección, 1942-1947
}

Laura Beatriz Moreno-Rodríguez

Académica investigadora

Universidad Nacional Autónoma de México

\section{Resumen}

José Figueres estuvo exiliado en México entre 1942 a 1947. Su exilio estuvo marcado por la relación que mantuvo con otros centroamericanos, quienes en aquellos años también fueron perseguidos políticos de los gobiernos de Nicaragua, El Salvador, Guatemala y Honduras, regímenes considerados como autoritarios en los comienzos de los años treinta del siglo xx. En la presente investigación cito algunos episodios que influyeron para que José Figueres, así como otros de sus con-

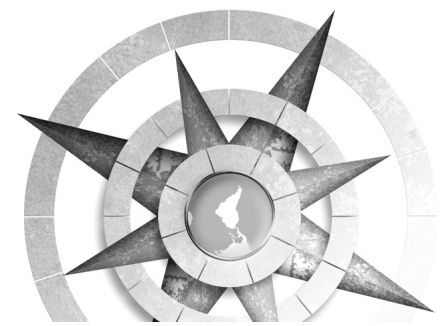

nacionales, fueran vigilados por el gobierno mexicano durante su estancia.

Palabras clave: José Figueres Ferrer, exilio costarricense en México, vigilancia política, Rafael Ángel Calderón Fournier, Temas de Nuestra América, Cátedra del Exilio

\section{Abstract}

José Figueres was exiled in Mexico between 1942 and 1947. His exile was marked by the relationship he rept with other Central Americans, who were, victims of political persecution by the governments of Nicaragua, El Salvador, Guatemala and Honduras, considered as regimes of authoritarian type. In this article I point out to some episodes that made José Figueres, as well as other of his contrymen, be under the vigilance of the Mexican government during his stay there. 
Keywords: José Figueres Ferrer, Costa Rican exile in México, political vigilance, Rafael Ángel Calderón Fournier, Exile Research Group, Temas de Nuestra América

\section{Introducción}

José Figueres estuvo exiliado en México entre 1942 a 1947, durante la Segunda Guerra Mundial, cuando las naciones de América Latina suscribieron el pacto de solidaridad hemisférica ante un posible ataque extra continental. Como parte de este pacto, fueron perseguidos, encarcelados y expulsados los latinoamericanos identificados con el nazifascismo y los ciudadanos de las naciones del Eje -Alemania, Italia y Japón- que residian en los distintos países del continente, acusados de realizar actividades de contraespionaje y de quintacolumnismo.

Este fue un periodo en que el gobierno mexicano, a través de su embajada en Costa Rica, demostró simpatía hacia el gobierno de Rafael Ángel Calderón Guardia (1940-1944), y también vivió momentos de tensión durante la presidencia de Teodoro Picado (1944-1948). En el interior del país, el exilio de Figueres estuvo marcado por la relación que mantuvo con otros centroamericanos, quienes en aquellos años también fueron perseguidos políticos de los gobiernos de Nicaragua, El Salvador, Guatemala y Honduras, regímenes considerados como autoritarios en los comienzos de los años treinta del siglo Xx.

Las actividades realizadas por los exiliados centroamericanos fueron registradas por los organismos de seguridad mexicanos, pues se evitaba a toda costa cualquier acto que pusiera en riesgo la estabilidad interna, así como su relación con las naciones de donde provenían.

En la presente investigación cito algunos episodios que influyeron para que José Figueres, así como otros de sus connacionales, fueran vigilados por el gobierno mexicano durante su estancia en el territorio. Estas indagaciones se explicarán mediante el contexto internacional; la relación que México mantuvo con los gobiernos de Costa Rica entre 1942 y 1947. Lo anterior permitirá contar con mayores elementos para comprender la importancia de la presencia de Figueres, que en 1948 fundó la Segunda República.

\section{México y Costa Rica al inicio de la guerra}

A principios de los años cuarentas, Rafael Ángel Calderón Guardia ocupó por primera vez la presidencia de Costa Rica. Su gobierno se distinguió por promover reformas sociales, laborales y 
políticas que beneficiaron a gran parte de la población. Impulsó el sindicalismo entre la clase trabajadora; con el Partido Republicano Nacional (PRN), -al que pertenecía-, logró consolidar una alianza con el Partido Comunista de Costa Rica -que a partir de 1943 se transformó en Partido Vanguardia Popular (PVP) - y con la Iglesia Católica, a fin de desarrollar una reforma social de corte populista. Tales medidas despertaron fuertes animadversiones entre la oligarquía y los sectores económicos más poderosos, de franca oposición al comunismo. La oposición criticó duramente al gobierno a través de la prensa y la radio, obligando a algunas personas a salir al exilio. ${ }^{1}$

Los informes de la Embajada de México en Costa Rica, lo describieron como un gobierno católico socialista, dentro de un límite estrecho del socialismo cristiano. Para el diplomático mexicano fue difícil clasificar la posición política del mandatario. Al final de su informe en 1941, anotó que el presidente mantenía una clara afinidad a la política de la Casa Blanca. ${ }^{2}$

1 Véase David Díaz Arias, Crisis social y memorias en lucha: Guerra civil en Costa Rica, 1940-1948, San José de Costa Rica, UCR, 2015.

2 Archivo Histórico Genaro Estrada de la Secretaría de Relaciones Exteriores de México (en adelante AHGE-SRE), exp. 29-28-11.
Con el inicio de la Segunda Guerra Mundial, Estados Unidos decidió proteger sus fronteras de un posible ataque extra continental, por lo que en 1940 estableció acuerdos con México para la defensa de la costa del Pacífico. En 1942, en el marco de una de las reuniones de Consulta de Ministros de Relaciones Exteriores, México y Costa Rica, junto con otras naciones de Latinoamérica, firmaron acuerdos para la defensa del hemisferio, dando como resultado la adopción de medidas de seguridad y vigilancia para el continente americano. En este sentido, el servicio confidencial mexicano tuvo un papel fundamental en la vigilancia de los grupos de extranjeros residentes en México, sobre todo de aquellos que pertenecían a las potencias del Eje.

Con respecto a estas medidas, el gobierno de Costa Rica, tras haber declarado la guerra, autorizó a las agencias policiales y de inteligencia investigar a los ciudadanos alemanes, italianos y japoneses, residentes en el país quienes quedaron bajo vigilancia especial del Estado. También se suspendieron los lazos comerciales con las potencias del Eje, declarando ilegales la importación o la exportación de productos de dichos países. En septiembre de 1942, el gobierno centroamericano notificó al Encargado de Negocios de Alemania, 
acreditado en aquel país, que se clausurarían los consulados costarricenses en la zona ocupada por las fuerzas alemanas, y que a partir de ese momento los cónsules y vicecónsules de Alemania en Costa Rica suspenderían sus actividades, debido a su intromisión en la política interna por medio de su Encargado de Negocios y del ministro residente en Guatemala. Este hecho fue aplaudido y apoyado por Estados Unidos, que ofreció su cooperación para el mantenimiento de la soberanía del país centroamericano. ${ }^{3}$

A partir de ese momento, los ciudadanos identificados como simpatizantes del nazifascismo fueron encarcelados, y otros hasta expulsados del país. En ese contexto, en Costa Rica y otras naciones de Latinoamérica, los delitos de guerra fueron utilizados para combatir a la oposición gubernamental. Ese fue el caso de José Figueres, quien tras un discurso en contra del gobierno de Calderón Guardia, fue detenido por la policía. La razón de este acto, fue que el coronel Eduardo Andino, agregado militar de la Legación de Estados Unidos, hizo presión para que a Figueres lo remitieran a uno de los campos de concentración de Estados Unidos, por ser nazi. ${ }^{4}$ Aunque nunca se le comprobó la

3 Ibid.

4 Guillermo Villegas Hoffmeister, La guerra de Figueres. Crónica de ocho años, Costa Rica, Editorial Universidad Estatal a Distancia, 1998. supuesta filiación nazifascista, lo cierto es que el acaudalado Figueres mantuvo relaciones de negocios con distintos ciudadanos alemanes que residían en Costa Rica; motivo que, en aquellos años, fue suficiente para considerarlo sospechoso.

\section{El exilio de Figueres: del unionismo a la insurrección, 1942-1944}

En julio de 1942, José Figueres emprendió un largo viaje al exilio: primero pasó por El Salvador, después por Guatemala, y finalmente llegó a México. Ahí se instaló en casa de la costarricense María Teresa Castro Cervantes, hermana del acaudalado hacendado Fernando Castro Cervantes, con quien mantuvo amistad por varios años.

Con la guerra en pleno apogeo, José Figueres encontró en la ciudad de México un lugar para continuar su campaña en contra del gobierno de Calderón Guardia. Hay que recordar que el conflicto bélico mundial atrajo a México a un exilio antifascista desde distintos lugares. La mayoría de los exiliados eran intelectuales, profesionistas, políticos y algunos acaudalados como el mismo Figueres. Su presencia, en ocasiones, permitió la conjunción de distintas ideologías y derivó en agrupaciones de corte democrático. En esos años el comunismo abrió las puertas a la unión

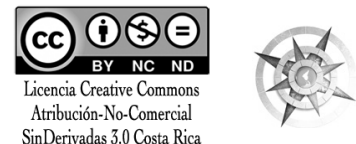


de fuerzas, tras el llamado a la formación de frentes populares, los cuales se gestaron desde finales de la década de los treinta y se fortalecieron en 1941, después de la invasión las fuerzas alemanas a la URSS por. El objetivo era fortalecer la democracia ante el autoritarismo que impulsaban los regímenes de los países del Eje. Esta conjunción de fuerzas democráticas también fue utilizada por los gobiernos autoritarios de Centroamérica, para mostrar a Estados Unidos que apoyaban el sistema democrático, principal bandera de lucha durante el conflicto bélico, y con esto ganar y mantener prebendas económicas que les redituaba la guerra.

El 22 de agosto de 1942, Carlos Mendieta viajó a Costa Rica para conformar una unión centroamericana, pero, según el informe del embajador mexicano en aquel país, éste era un ciudadano nicaragüense y un líder caprichoso, por lo que su propuesta tuvo poca respuesta en los medios costarricenses, y el gobierno dijo no tener conocimiento de sus actividades. Se decía que Mendieta era apoyado por Anastasio Somoza y que pronto se llevaría a cabo un congreso en el que se reunirían los principales líderes de la región. En opinión del diplomático mexicano, esta oferta probablemente tendría alguna simpatía entre diferentes elementos de los demás países, pero distaba mucho de tener fuerza popular de importancia que permitiera -si la reunión se llevaba a cabo-, tener algún impacto en la región; además de que Somoza jamás haría algo que beneficiara a cualquier país centroamericano. ${ }^{5}$ En ese contexto, en México se estaba conformando la Unión Democrática Centroamericana (UDC), liderada por el costarricense Vicente Sáenz, junto con otros personajes de importancia política, económica y cultural de las cinco naciones centroamericanas que se encontraban también en el exilio. Esta Unión fue apoyada por el mexicano y líder sindical Vicente Lombardo Toledano, quien desde los años treinta mantenía una relación amistosa con ese intelectual costarricense. Cabe recordar que Lombardo Toledano, fundó la Universidad Obrera en la ciudad de México, además de impulsar medidas en beneficio de la clase trabajadora de México y del continente, a través de la Confederación de Trabajadores de América Latina (CTAL), creada en 1938. Dicho organismo luchó por la elevación del nivel de vida del pueblo, por el desarrollo económico y por la industrialización de los países; así como para combatir a todas las fuerzas que pudieran oponerse a la consecución de estos propósitos, principalmente

5 AHGE-SRE, exp. 23-30-15. 
a la amenaza del fascismo y del imperialismo. ${ }^{6}$ Mantuvo una cercanía con las fuerzas democráticas de Nicaragua, Cuba y Costa Rica, entre otras, a la vez que estrechó sus lazos con mandatarios como Anastasio Somoza, quien en 1944 lo invitó a presidir un acto a favor de su gobierno.?

En noviembre de 1942 hubo una fuerte movilización sindical en Costa Rica, que fue apoyada por el propio Lombardo Toledano quien, en una carta dirigida a la Embajada de México en aquel país, señaló que había fuerzas opositoras y de exiliados en territorio mexicano que intentaban derrocar al gobierno de Calderón Guardia y mermar los derechos de los trabajadores mediante la desaprobación de una legislación impulsada por el sindicalismo obrero. ${ }^{8}$ Existen algunas evidencias que señalan la animadversión de Lombardo Toledano, respecto a la forma de lucha de José Figueres, así como su simpatía hacia Vicente Sáenz. Se puede suponer que la información que obtuvo el líder sindical mexicano se dio mediante su acercamiento al jefe del partido conservador de Nicaragua

6 Patricio Bernardo Herrera González, "A favor de una patria para los trabajadores. La Confederación de Trabajadores de América Latina y su lucha por la emancipación del continente, 19381953", tesis de doctorado en Historia. El Colegio de Michoacán, 2013.

7 AHGE-SRE, exp. III-2481-12.

8 AHGE-SRE, exp. 23-30-15.
Emiliano Chamorro, también exiliado en México, y que en ese año mantenía una relación con Figueres. ${ }^{9}$

En un informe confidencial del 16 de febrero de 1944, el embajador mexicano Roberto Córdova llegó a Costa Rica en pleno proceso electoral. Fue recibido por el candidato presidencial Teodoro Picado y por el jefe del Partido Vanguardia Popular, Manuel Mora Valverde, quienes buscaron conocer el sentir del gobierno de México sobre la situación política costarricense. El embajador notó la intranquilidad existente por los resultados que se obtendrían en la elección presidencial, ya acentuada, debido a los rumores sobre una acción conjunta de Guatemala, El Salvador y Honduras en contra de la soberanía de Costa Rica: "Expresamente se refirieron al peligro de que el Partido de oposición al gobierno del presidente Calderón Guardia contara con el apoyo de esos países para obtener armas, elementos de propaganda y dinero" ${ }^{10}$ También hicieron alusión a las noticias de prensa llegadas desde México relativas a la denuncia que ante el gobierno mexicano hizo Lombardo Toledano respecto del envío de armas a Costa Rica con fines subversivos. ${ }^{11}$

9 Véase Laura Beatriz Moreno Rodríguez, Exilio nicaragüense en México (1937-1947), México, UNAMCIALC, 2015, (Colección Exilio iberoamericano), núm. 4.

10 AHGE-SRE, exp. 23-40-50.

11 Ibid. 
Ante esa situación, Roberto Córdova manifestó que el presidente Ávila Camacho y el secretario de Relaciones Exteriores, Ezequiel Padilla, no omitirían ningún esfuerzo para evitar que cualquier partido político costarricense aprovechara la hospitalidad mexicana para conspirar en contra de un gobierno amigo. Pocos días después de esta preocupación, expuesta por políticos de aquel país, los servicios confidenciales comenzaron la vigilancia hacia las actividades que estaba realizando José Figueres. Se reportó que: " [...] se sospechaba que los costarricenses José Figueres y Juan Vicente Lorenzo Brenes, viajarían a Guatemala para recoger armas y parque, para ayudar a elementos oposicionistas en Costa Rica, quienes no estaban de acuerdo con el gobierno de Rafael Calderón Guardia. Según el inspector, José Figueres denunciaba que el gobierno de ese país le acusaba de mantener una relación de negocios con un espía nazi de nombre Federico Reimer". ${ }^{12}$ Por lo anterior, a Figueres se le acusó de actuar a favor de los países del Eje, lo que motivó que el gobierno buscara su salida del país. Además, informó que en ese momento encabezaba un movimiento de tipo político entre los

12 Archivo General de la Nación, sección, Dirección General de Investigaciones Politicas y Sociales ( en adelante AGN, DIPS), caja. 89, exp. 13, fs. 341-342. estudiantes costarricenses que residían en México, quienes se manifestaron de manera negativa sobre los gobiernos de México y de Costa Rica. Estos datos se obtuvieron, según el agente, porque la Secretaría de Gobernación (Segob) interceptó cartas de Fernando Montes de Oca, simpatizante de Figueres, en las que expresó conceptos injuriosos en contra del gobierno mexicano, lo que causó su deportación el día 8 de septiembre de $1942 .{ }^{13}$

A lo largo del proceso electoral que se vivía en Costa Rica, los agentes mexicanos mantuvieron una estrecha vigilancia de Figueres y algunos otros sospechosos. Las indagaciones permitieron que el embajador mexicano declarara a los diarios de circulación nacional en Costa Rica sobre la disposición de su gobierno para impedir que en el territorio y, con armas mexicanas, se conspirara contra la paz y la tranquilidad de las naciones vecinas. Evitaría a toda costa que movimientos revolucionarios se levantaran en contra de los gobiernos constitucionales del continente. ${ }^{14}$

Si bien, como medida diplomática, México se abstuvo de tomar partido entre picadistas y cortesistas, lo cierto es que el ministro y el embajador de

\footnotetext{
13 Ibid.

14 AHGE-SRE, exp. 23-40-50
} 
Estados Unidos sabían que Teodoro Picado llegaría a la presidencia sólo mediante el fraude, debido a que los simpatizantes de León Cortés eran una abrumadora mayoría. En ese sentido, era obvio que los exiliados en México intentaran mediante las armas deponer al actual gobierno y con ello impedir la imposición de Picado en la presidencia. Aun con todo este conocimiento, México se abstuvo de entrometerse en la política de aquel país centroamericano. Sin embargo, era evidente la simpatía del diplomático hacia el mandatario Calderón Guardia, quien se lo había manifestado desde 1941.

Hasta 1944 el embajador mantuvo una comunicación constante con Calderón Guardia y Mora Valverde, quien en reiteradas ocasiones le consultaba al embajador sobre la posición que debía tomar su partido frente a las manifestaciones y amenazas de los cortesistas. A escasos días de la elección, Mora Valverde señaló al gobierno mexicano, que de presentarse actos de violencia, mandaría al exilio a los oposicionistas o buscaría que éstos solicitaran asilo político en la Embajada mexicana con la finalidad de evitar derramamiento de sangre. No obstante, durante las elecciones no fue necesario recurrir a dicha medida: con 76, 341 votos, Teodoro Picado ganaba la presidencia de Costa Rica frente a su rival León Cortes. ${ }^{15}$
Mientras tanto en México, al conocerse el triunfo de Picado, Figueres buscó por todos los medios conseguir aliados para terminar con el nuevo gobierno.

\section{De la insurrección a la Legión: 1944-1947}

Durante su toma de posesión como presidente de la República Teodoro Picado, dio su primer discurso, en el cual, según el embajador de México, hizo una fuerte crítica a la política agraria mexicana, manifestando que la distribución de tierras en su país no consideraría las expropiaciones, como tampoco para el caso de las compañías petroleras. Según el diplomático, Picado hizo este comentario con la finalidad de agradar a los representantes de Estados Unidos que se encontraban en el acto. ${ }^{16}$

Las impresiones del embajador mexicano eran que el pueblo costarricense creía que México tuvo una importante influencia en el gobierno de Calderón Guardia, debido a que el 5 de octubre de 1943 se inauguró la Confederación de Trabajadores de Costa Rica, a la que asistió como invitado especial Lombardo Toledano, presidente de la Confederación de Trabajadores de América Latina (CTAL), el cual, además vino a rendir homenaje expreso a quien en ese momento era presidente de Costa Rica, por el

16 AHGE-SRE, exp. III-451-2.

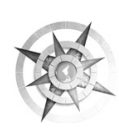


impulso legislativo y político que había hecho en materia laboral. Otro elemento que es considerado de dependencia política de los costarricenses; fue la reanudación de relaciones entre el país centroamericano y la Unión de Republicas Socialista Soviéticas (URSS); aunque ésta fue encauzada por el gobierno mexicano, se llevó a cabo a solicitud del propio presidente Calderón Guardia. ${ }^{17}$

Aun con estas diferencias, el gobierno mexicano se vio obligado a mantener controladas las actividades de los exiliados, que en 1944 ya representaban un verdadero peligro para el gobierno de Teodoro Picado.

En ese año, José Figueres estuvo en contacto con el nicaragüense Rosendo Argüello, quien, de acuerdo con lo que expresó en sus memorias, Figueres estaba buscando armas para derrocar al régimen de Costa Rica, por lo que le sugirió que se agruparan en torno a la UDC, en donde actuaban personas de reconocido idealismo, como Vicente Sáenz, Pedro Zepeda, Juan José Meza y Ricardo Alduvín. En respuesta, según Argüello, Figueres dijo "[...] que en su concepto eran demasiado teorizantes, y que debíamos de formar un grupo aparte compuesto de gente inspirada en principios, pero que fueran de ac-

17 Ibid. ción", ${ }^{18}$ por lo que decidió aliarse a los nicaragüenses conservadores, liberales y sandinistas que conformaron el Comité Antisomocista.

En 1945, Argüello ya había establecido contacto con Pedro Zepeda, Emiliano Chamorro y Carlos Pasos Leyva, todos miembros del Comité Antisomocista y veteranos de guerra. Argüello buscó a sus compatriotas exiliados en México, para plantearles que, con el fin de derrocar a Somoza, primero debían entrar por Costa Rica, porque obteniendo bases en ese país el éxito estaba asegurado, ya que José Figueres y su grupo "volcarían sus arsenales, nos brindarían recursos y repetiríamos juntos ticos y nicas, la gesta del $56 "{ }^{19}$

Sobre este hecho, existen dos versiones: Rosendo Argüello sostiene en sus memorias que fueron los nicaragüenses los que se unieron a la campaña costarricense; y Guillermo Villegas, en La Guerra de Figueres. Crónica de 8 años, menciona que fue Figueres el que se unió a los nicaragüenses. Esta polémica, al parecer, nació a partir de la obtención de recursos para la compra de armas.

18 Rosendo Argüello, Quiénes y cómo nos traicionaron, Costa Rica, Editorial San José de Costa Rica, 1955, p. 12 .

19 Ibid. 
Durante 1946, ambos grupos aportaron dinero, pero en diversas ocasiones el armamento fue requisado por el gobierno mexicano, y en otras se acusaron de que las obtenidas por los nicaragüenses fueron de mala calidad. Lo cierto es que fue con el dinero de los conservadores con el que se compró la mayor parte del arsenal en México, pero, al salir del país a finales del 46 , este fue retenido por las autoridades mexicanas.

Al llegar a Guatemala se hizo la nueva compra mediante aportaciones de guatemaltecos, de costarricenses y de los nuevos exiliados que se unieron a la campaña. Esto lo demuestra una serie de informes de los servicios confidenciales mexicanos y algunas crónicas. Además, al parecer, cada grupo -nicaragüense/ costarricense- creyó que las acciones armadas iniciarían en su país de origen, al menos así fue para Emiliano Chamorro y el resto de los conservadores. Para los generales nicaragüenses era apremiante la lucha armada para la caída del régimen somocista antes de las elecciones de 1947, con el propósito de retomar el poder lo antes posible y recuperar el control de Nicaragua, como lo habían hecho desde la independencia de esa nación.

En Guatemala, en 1947, año en que se firmó el Pacto del Caribe, el ala conservadora tuvo menos fuerza a con- secuencia de dos hechos: el primero fue en abril de 1946, cuando el líder de los liberales en el exilio, Carlos Pasos Leyva, abandonó la empresa, debido a que había arreglado satisfactoriamente las diferencias con Somoza y le había autorizado su retorno a Nicaragua; ${ }^{20}$ el segundo, según informes confidenciales mexicanos, Pasos Leyva tardó en salir de México, lo que posibilitó que traicionara a los nicaragüenses y costarricenses involucrados en la campaña insurreccional, pues las autoridades mexicanas obtuvieron informes sobre la salida de un cargamento de armas con dirección a Costa Rica. El resultado fue el decomiso del equipo bélico y la detención de Argüello, el poeta Guillermo Castelón y Edelberto Torres, acusados de realizar actividades sediciosas.

Tras este hecho, Rosendo Argüello, al igual que otros exiliados nicaragüenses, se dirigió a Guatemala para continuar con el plan, ya que en México no existían las condiciones necesarias para seguir adelante. Junto con él llegaron otros emigrados, el nicaragüense Emiliano Chamorro y los dominicanos Juan Rodríguez García, Horacio Ornes y Juan Bosch. Lo que sucedió después de esa fecha definió en gran parte el proyecto de la Legión y de sus integrantes.

20 AGN, DGIPS, caja. 784, exp. 9, f. 10. 